\title{
ASSESSING CONTROL OF ASTHMA IN JUSH, JIMMA, SOUTH WEST ETHIOPIA
}

\author{
Kirubel Zemedkun ${ }^{1}$, Kifle Woldemichael ${ }^{2}$, Gobezie Tefera ${ }^{1}$
}

\section{ABSTRACT}

BACKGROUND: Despite international guidelines, asthma control is short of the goal in different parts of the world. The objective of this study was to assess control of asthma in patients older than 14 years at the Chest Clinic of Jimma University Specialized Hospital/JUSH, South West Ethiopia.

METHODS: A cross-sectional hospital-based study was conducted on 234 physician-diagnosed asthmatic patients attending the chest follow up clinic from June 01 to July 31, 2012. Asthma control was assessed using the GINA algorithm and the ACT questionnaire. Pulmonary function test was measured using a spirometer for 160 subjects. Data were cleared, entered and analyzed using SPSS version 16 and independent variables were assessed for association with the level of asthma control using bivariate and multinomial analyses.

RESULTS: Using the GINA based algorithm, 42 respondents (26.2\%) were considered to have partly controlled asthma and the majority, 117 (76.1\%), had uncontrolled asthma. Asthma was uncontrolled (ACT score $<19)$ in $71.4 \%$ subjects and well-controlled $(A C T$ score $=20-25)$ in $28.6 \%$. Inhaled corticosteroids alone or in association with long-acting $b$-agonists, which are the prophylactic treatments recommended by GINA, were used by only 9 subjects (3.8\%). Factors associated independently with asthma control were individual patient's age group, unscheduled visit, frequency of SABA use, type of treatment and perceived rate of asthma control.

CONCLUSION: Asthma control is unacceptably poor in Jimma, South West Ethiopia. This could be changed through improved appropriate treatment and frequent monitoring to achieve and maintain control.

KEYWORDS: Control of asthma, Spirometry, Asthma treatment, Sub-Saharan Africa

DOI: http://dx.doi.org/10.4314/ejhs.v24i1.7

\section{INTRODUCTION}

Asthma is a chronic inflammatory disorder of the airways. Chronically, inflamed airways are hyperresponsive-they become obstructed and airflow is limited by broncho-constriction, mucus plugs, and increased inflammation when airways are exposed to various risk factors. The goal of asthma treatment is to achieve and maintain clinical control that can be reached in most patients through a continuous cycle that involves assessing asthma control, treating to achieve control, and monitoring to maintain control(1). Asthma control can be broken down into two domains: impairment and risk. Impairment is an assessment of the frequency and intensity of symptoms and functional limitations that a patient is experiencing or has recently experienced. Risk is an estimate of the likelihood of either asthma exacerbations or of progressive loss of pulmonary function over time (2).

There are different validated measures for assessing impairment to determine control of asthma, one of which is The Global Initiative for Asthma (GINA) guideline which has proposed six criteria for evaluating asthma control. Controlled asthma is defined by the absence of daytime symptoms (no more than twice a week), the

\footnotetext{
${ }^{1}$ Department of Internal Medicine, Jimma University, Jimma, Ethiopia

${ }^{2}$ Department of Epidemiology, Jimma University, Jimma, Ethiopia

Corresponding Author: Kirubel Zemedkun Gebreselassie, Email: Kirubelz42@gmail.com
} 
absence of night-time symptoms, no limitations in activities, no need for rescue medication (no more than twice a week), normal lung function (measured as forced expiratory volume in one second or peak expiratory flow) and no exacerbations(3).

The validated and international asthma control test (ACT) questionnaire has also been developed to facilitate and standardize the assessment of the impairment domain of asthma control. The ACT survey is a patient-completed questionnaire with 5 items assessing asthma symptoms (daytime and nocturnal), use of rescue medications, and the effect of asthma on daily functioning. Each item includes 5 response options corresponding to a 5-point rating scale. In scoring the ACT survey, responses for the 5 items are summed to yield a score ranging from 5 (poor control of asthma) to 25 (complete control of asthma. 8\%). A cut-off point $<1$ was used for under control of asthma which has a sensitivity of $71.3 \%$ and specificity of 70. ACT scores also correlated significantly with baseline percent predicted Forced Expiratory Volume in one second (FEV1) (4).

Exacerbations of asthma are episodes of a progressive increase in shortness of breath, cough, wheezing, or chest tightness, or a combination of these symptoms requiring systemic steroids or emergency department visits and admission (1).

Assessment of the risk of exacerbations can be inferred from the medical history. Patients who have had exacerbations requiring emergency department (ED) visits, hospitalization or intensive care unit (ICU) admission, especially in the past year, have a great risk of exacerbations in the future (2).

The test most used for assessing the risk of future adverse events is spirometry, especially forced expiratory volume in 1 second (FEV1) expressed as a percent of the predicted value or a proportion of the forced vital capacity (FVC) or FEV1/FVC. A low forced expiratory volume in one second (FEV1) is associated with an increased risk of asthma exacerbations-the lower the FEV1, the greater the risk (5).

\section{METHODS AND MATERIALS}

The study was carried out in Jimma University Specialized Referral Hospital (JUSH), one of the prestigious teaching medical institutions of the country. The hospital, as a referral center for 15 million populations in the Southwest region of Ethiopia, gives health service at inpatient and outpatient levels. It has one chest clinic. There are 833 patients with regular follow-up in the clinic currently. Of these, 331 are males while 502 are females. A cross-sectional hospital-based survey was conducted from June 1, 2012 to July 31, 2012.

Physician diagnosed asthmatic patients with follow-up at the chest clinic and taking medications for their asthma, both male and female aged $>14$ years, were included in the study. Pregnant ladies were excluded from the study due to variable effects of pregnancy on bronchial asthma. Patients with diagnosis other than asthma such as physician diagnosed COPD, bronchiectasis, lung cancer, and cardiac illness were also excluded due to confounding effects. Patients with significant respiratory distress due to an exacerbation that required emergency department visit or admission were not included in the study as they are not able to perform spirometric measurement.

The sample was calculated using the single population formula assuming control of asthma to be $50 \%$, margin of error $5 \%$, and $95 \%$ confidence interval. Accordingly, calculated sample size was 384. Since the source population was less than 10,000 , correction factor to determine the final sample size was used, and the sample became 263 . Consecutive sampling of clients coming to the clinic on their appointment dates was conducted. Pulmonary function test was carried out using a spirometer for 160 subjects $(68 \%)$ of the total sample size who came to the chest clinic consecutively on the day of appointment.

Asthma control was assessed in two ways: using the GINA classifications scheme and ACT score. The characteristics of GINA clinical classification used in the study were daytime symptoms, nocturnal symptoms, need for reliever medication, limitation of activity, number of exacerbations and lung function test, FEV1(1). For patients whose lung function test was not determined, only the five components of GINA algorithm, excluding the FEV1 was used to assess control of asthma separately.

The validated and international asthma control test (ACT) questionnaire was used to assess the control of asthma. The ACT survey is a 
patient-completed questionnaire with 5 items assessing asthma symptoms (daytime and nocturnal), use of rescue medications and the effect of asthma on daily functioning. Each item includes 5 response options corresponding to a 5point rating scale. In scoring the ACT survey, responses for each of the 5 items were summed to yield a score ranging from 5 (poor control of asthma) to 25 (complete control of asthma). A cutoff point $<19$ was used for under control of asthma (2).

Patients were also classified into four severity categories using the NAEPP 2007 classification system as mild intermittent, mild persistent, moderate persistent, and severe persistent asthma. Data for this study were collected through patient interview using a structured questionnaire containing socio-demographic characteristics, asthma symptoms, type and frequency of treatment, number of exacerbations, and certain predictors of asthma control were used to assess control of asthma.

Pulmonary function test was determined that generates FEV1 and FEV/FVC. A portable minidigital spirometer (DATOSPIR-120-Model-D designed by SIBELMED) was used. It has its own disposable mouth piece and a connecting tube.

A trained nurse entered correct values for age, height and gender as these values are used to generate the appropriate predicted values for the individual patient. Height was measured with shoes off. Body weight was also measured to calculate the body mass index.

The patients were seated during spirometry. They were instructed to hold their nose with their first two fingers to prevent air leakage through their nasal passages. Deep inhalation occurred before the mouthpiece was placed in the mouth. Immediately after the deep inhalation, the mouthpiece was placed just inside the mouth between the teeth. The lips were sealed tightly around the mouthpiece to prevent air leakage during maximal forced exhalation. Three maneuvers were performed, and the highest spirometric value was taken for analysis. Universal pre-requisitions of performing spirometric assessment were carried out.
A total of four nurses who were working at the chest follow-up clinic were involved in the study after they were trained on how to fill the structured questionnaire. Two of the nurses were also trained on how to perform the spirometer. The principal investigator supervised the overall activities during data collection.

SPSS statistical software, Version 16.0 was used for data analysis. Inter-group comparisons were performed with the chi-square test or Fisher's Exact Test for categorical variables. The variables reported on the questionnaire were assessed for association with the level of asthma control. In a first step, each variable was evaluated independently in a bivariate analysis. Next, all variables associated with the level of asthma control at a probability level of 0.25 in one or other of the univariate analyses were entered into a multinomial logistic regression analysis. Variables were retained in the model in an ascending stepwise manner to generate odds ratio and determine those that were independently associated with the level of asthma control at a probability level of 0.05 .

The data were checked for completeness and consistency on the day of collection. Standards of procedures during spirometry were re-checked by the principal investigator. Ethical clearance was obtained from Ethical Committee of Jimma University. The willingness and verbal informed consent were obtained from the study participants before inclusion into the study.

\section{RESULTS}

Overall, 234 individuals (89\% of the calculated sample size) fulfilled the eligibility criteria and were included in the study. Of these, spirometry to generate the FEV1 was done for 160 (68\%) subjects.

Daytime asthma symptoms that occurred daily were reported by $80(34.2 \%)$ of the subjects, and night time asthma symptoms occurred 7 times per week in $94(40.2 \%)$ subjects. Eighty-nine (38\%) individuals used SABA more than twice per week to relieve their symptoms (Table 1). 
Table 1: Socio-demographic and health characteristics of subjects with asthma, Chest Clinic JUSH, 2012

\begin{tabular}{|c|c|c|}
\hline Variable & No & $\%$ \\
\hline \multicolumn{3}{|l|}{$\begin{array}{l}\text { Age } \\
\text { Mean } \pm \mathrm{SD}=41.41 \pm 15.194\end{array}$} \\
\hline \multicolumn{3}{|l|}{$\operatorname{Median}($ Range $)=40(14-82)$} \\
\hline 14-34 & 77 & 32.9 \\
\hline $35-54$ & 99 & 42.3 \\
\hline$>=55$ & 58 & 24.8 \\
\hline \multicolumn{3}{|l|}{ Sex } \\
\hline Male & 103 & 44 \\
\hline Female & 131 & 56 \\
\hline \multicolumn{3}{|l|}{ Living place } \\
\hline Urban & 217 & 92.7 \\
\hline Rural area & 17 & 7.3 \\
\hline \multicolumn{3}{|l|}{ Smoking } \\
\hline Yes & 7 & 3.0 \\
\hline No & 227 & 97.0 \\
\hline \multicolumn{3}{|l|}{ Co morbid illness } \\
\hline Yes & 75 & 32.1 \\
\hline No & 159 & 67.9 \\
\hline \multicolumn{3}{|l|}{ BMI } \\
\hline$<18$ & 54 & 23.1 \\
\hline $18-25$ & 131 & 56.0 \\
\hline $25-30$ & 34 & 14.5 \\
\hline$>\mathbf{3 0}$ & 15 & 6.4 \\
\hline \multicolumn{3}{|l|}{ Educational level } \\
\hline Illiterate & 65 & 27.8 \\
\hline Primary & 58 & 24.8 \\
\hline Secondary & 63 & 26.9 \\
\hline Higher education & 48 & 20.5 \\
\hline \multicolumn{3}{|l|}{$\begin{array}{l}\text { Frequency of daytime Asthma } \\
\text { symptoms }\end{array}$} \\
\hline None & 21 & 9.0 \\
\hline$<2$ days/week & 42 & 17.9 \\
\hline$>2$ days/week & 76 & 32.5 \\
\hline Daily & 80 & 34.2 \\
\hline Throughout the day & 15 & 6.4 \\
\hline
\end{tabular}

Asthma control was initially assessed using the GINA algorithm, and based on this method, 42 respondents $(26.2 \%)$ were considered to have partly controlled asthma and the majority, 117 (73.1\%), had uncontrolled asthma. Since spirometry was done only for $68 \%$ of the

\begin{tabular}{|c|c|c|}
\hline $\begin{array}{ll}\text { Variable } & (\mathrm{n}=234)\end{array}$ & No & $\%$ \\
\hline \multicolumn{3}{|l|}{ Night time Asthma symptoms } \\
\hline None & 33 & 14.1 \\
\hline $1-2 /$ month & 14 & 5.9 \\
\hline 3-4/month & 41 & 17.5 \\
\hline >1/week & 52 & 22.2 \\
\hline 7 times/week & 94 & 40.2 \\
\hline \multicolumn{3}{|l|}{ Frequency of SABA use } \\
\hline None & 110 & 47.0 \\
\hline$<=2$ days/week & 35 & 15.0 \\
\hline >2 days/week & 39 & 16.7 \\
\hline Several times/day & 50 & 21.4 \\
\hline \multicolumn{3}{|l|}{ Limitation of activity } \\
\hline None & 70 & 29.9 \\
\hline Any & 164 & 70.1 \\
\hline \multicolumn{3}{|l|}{ Perceived control of asthma } \\
\hline Uncontrolled & 150 & 64.1 \\
\hline Controlled & 84 & 35.9 \\
\hline \multicolumn{3}{|l|}{ Exacerbation } \\
\hline Yes & 24 & 10.3 \\
\hline No & 210 & 89.7 \\
\hline \multicolumn{3}{|l|}{ Unscheduled visit } \\
\hline Yes & 73 & 31.2 \\
\hline No & 161 & 68.8 \\
\hline \multicolumn{3}{|l|}{ Hospital admission } \\
\hline Yes & 29 & 12.4 \\
\hline No & 205 & 87.6 \\
\hline \multicolumn{3}{|l|}{ FEV1 } \\
\hline$>=80 \%$ & 23 & 14.4 \\
\hline $60-80 \%$ & 47 & 29.4 \\
\hline$<60 \%$ & 90 & 56.2 \\
\hline \multicolumn{3}{|c|}{ Family history Bronchial Asthma } \\
\hline Yes & 61 & 26.1 \\
\hline No & 173 & 73.9 \\
\hline \multicolumn{3}{|l|}{ Asthma Control ACT } \\
\hline Well Controlled & 67 & 28.6 \\
\hline Not Well Controlled & 49 & 20.9 \\
\hline Very Poorly Controlled & 118 & 50.4 \\
\hline
\end{tabular}

participants, asthma control using the GINA algorithm was done also for all the 234 patients excluding the lung function test component. Based on this method, asthma control was considered better than the one with lung function test (Fig 1). 


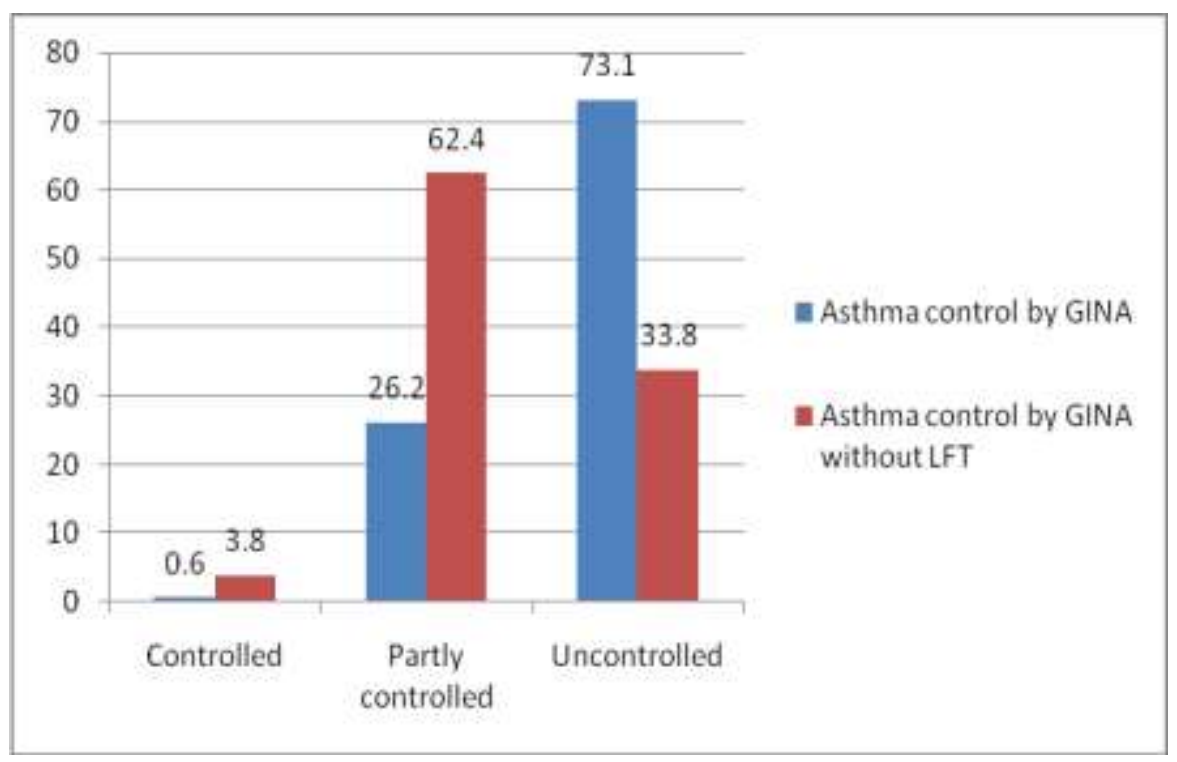

Fig.1: Proportion of subjects assigned to three different control groups using the GINA based algorithm with and without LFT, Chest Clinic, JUSH, 2012.

Asthma control was also assessed using the ACT score for all 234 individuals; 118 subjects $(50.4 \%)$ scored less than or equal to 15 that corresponds to very poorly controlled asthma, and only $67(28.6 \%)$ scored 20 and more than 20 out of 25 that corresponds to well controlled (Table 1).

Overall, 130(55.6\%) individuals used short acting beta agonist (SABA) inhaler medication for quick relief of their asthma symptoms. Inhaled corticosteroids alone or in association with longacting b-agonists, which are the prophylactic treatments recommended by GINA, were used by only 9 subjects $(3.8 \%)$. Oral corticosteroid was used by $28.6 \%$ of the individuals overall and use of theophedrine accounted for $17.5 \%$ of the asthmatic individuals (Fig. 2). Further analysis of treatment revealed that multiple drug therapy (two drugs $43.6 \%$, three drugs $17.9 \%$ ) was opted for a significant number of patients as compared to single drug therapy (29.9\%). Oral and inhaler SABA medications were the two most often prescribed combination of medicines.

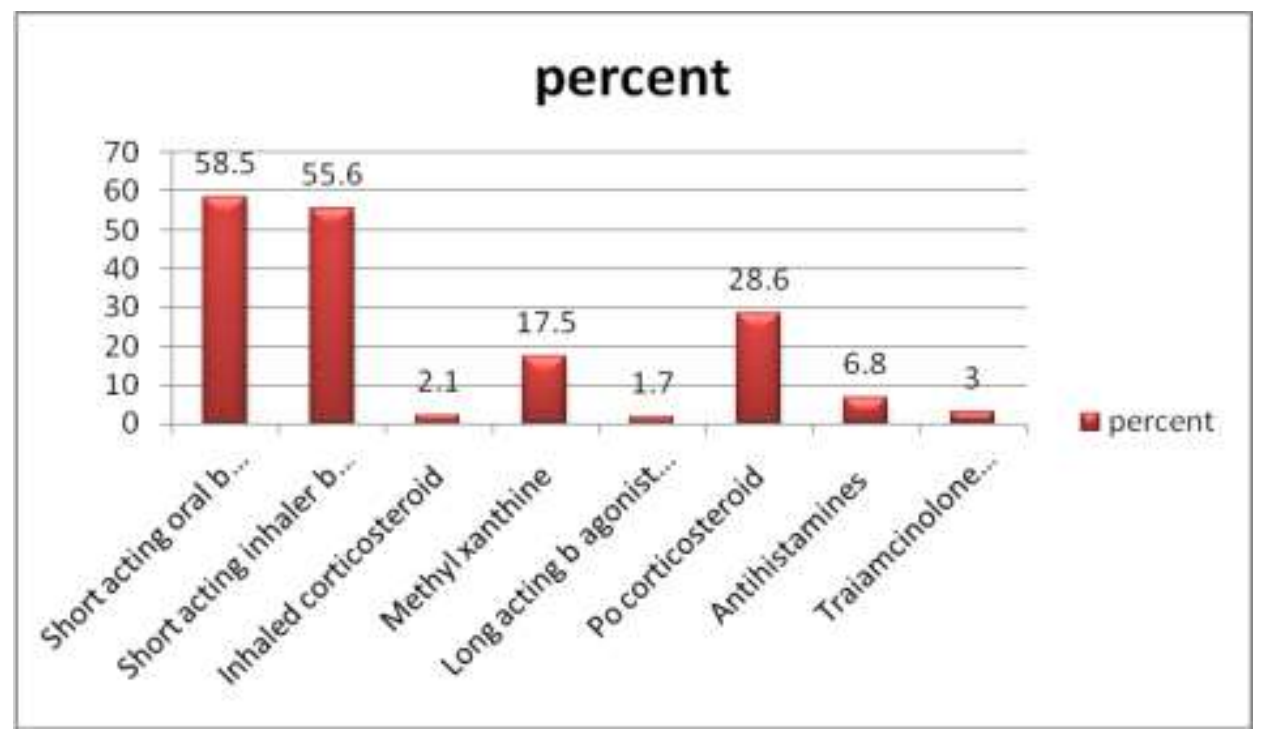

Fig.2: Proportion of subjects by type of treatment, 2012 chest clinic JUSH. (Multiple responses were possible). 
Only $1 \%$ of the patients with severe persistent asthma used a controller medication, which was an inhaled corticosteroid. At the same time, use of quick-relief medication such as a SABA was high in this group (85\%), which is suggestive of poor asthma control. Patients with intermittent asthma were found inappropriately receiving an inhaled corticosteroid (Fig.3).

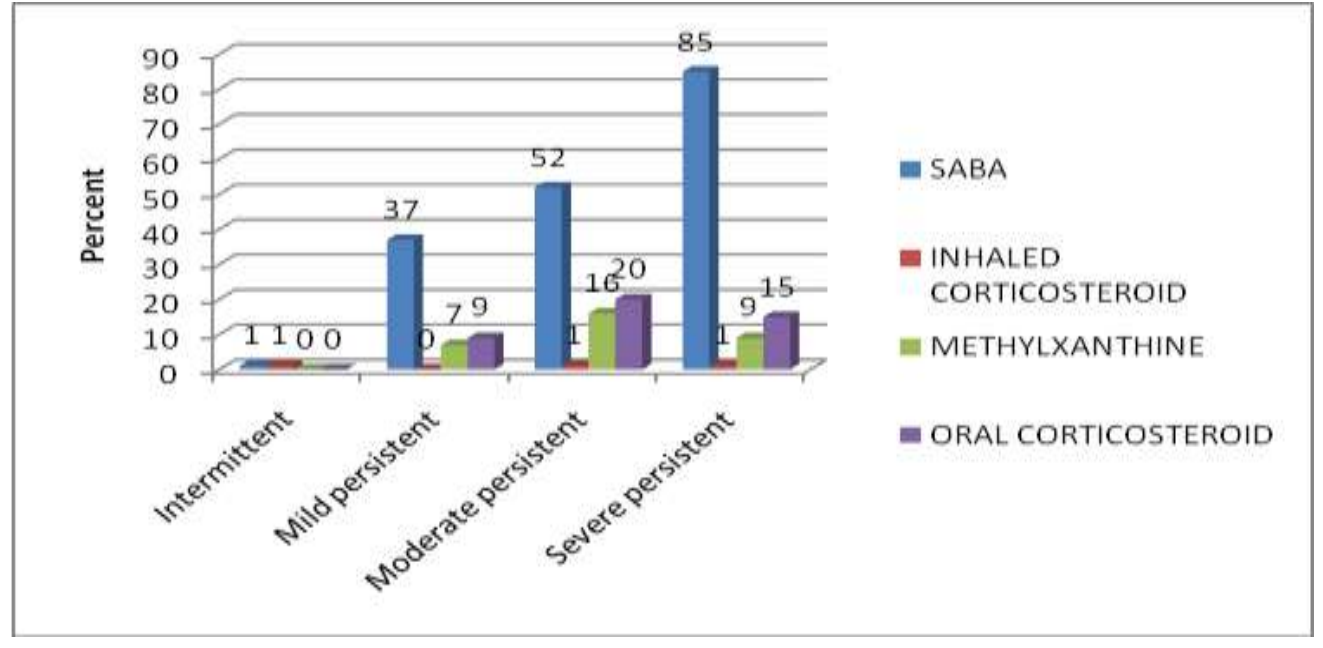

Fig.3: Use of medication by type of asthma severity, 2012 chest clinic JUSH.

Bivariate analysis identified a number of variables featured in the questionnaire as being associated with asthma control. Six of these were associated with control at a probability threshold of $\mathrm{p}<0.05$, and additional four variables at a probability level of $p<0.25$, which was the threshold required for entry into the multinomial analysis. These variables are listed in Table 3. The six variables with the strongest association with asthma control ( $p<0.05)$ were living place, BMI, unscheduled visit in the past one year, type of treatment for asthma, personal rate of asthma control in the past four weeks and underlying asthma severity. The four variables at probability level of $\mathrm{p}<0.25$ were age of the individual asthmatic patient, smoking history, presence of co-morbid illness and hospital admission in the past one year (Table 2).

All the ten variables retained were entered into a stepwise multinomial logistic regression analysis with retained five factors that were independently associated with asthma control. These were age group, frequency of unscheduled visit, use of inhaler SABA and OCS medications and personal rate of asthma control. Probability of getting well-controlled asthma was more than three times higher in the age group of 14-34 years than other older age groups, $\mathrm{p}=0.048(\mathrm{OR}=3.445$ 95\% CI (1.009-11.766)). Asthma was less wellcontrolled in those patients with more unscheduled visit $\mathrm{p}=0.002$ (OR=0.197 95\% CI (0.070-0.555)), in those using frequent SABA $\mathrm{p}=0.001(\mathrm{OR}=0.19$ 95\% CI (0.074-0.488)), OCS use $\mathrm{p}=0.011$ $(\mathrm{OR}=0.247$ 95\% CI (0.084-0.728)) and those who perceived their asthma is under controlled, $\mathrm{p}<0.001 \quad(\mathrm{OR}=0.05195 \%$ CI $(0.020-0.128))$ as indicated in Table 3. 
Table 2: Demographic and health characteristics of subjects with asthma by control status using ACT Questionnaire $(\mathrm{n}=234), 2012$ chest clinic JUSH.

\begin{tabular}{|c|c|c|c|c|}
\hline & $\begin{array}{c}\text { Well } \\
\text { Controlled }\end{array}$ & $\begin{array}{c}\text { Not-well } \\
\text { Controlled }\end{array}$ & $\begin{array}{c}\text { Very-poorly } \\
\text { controlled }\end{array}$ & P-Value \\
\hline \multicolumn{5}{|l|}{ Age } \\
\hline 14-34 & $27(35.1)$ & $20(26.0)$ & $30(39.0)$ & 0.172 \\
\hline $35-54$ & $25(25.3)$ & $17(17.2)$ & $57(57.6)$ & \\
\hline$>=55$ & $15(25.9)$ & $12(20.7)$ & $31(53.4)$ & \\
\hline \multicolumn{5}{|l|}{ Living place } \\
\hline Urban & $65(30.0)$ & 41(18.9) & $111(51.2)$ & 0.017 \\
\hline Rural area & $2(11.8)$ & $8(47.1)$ & $7(41.2)$ & \\
\hline \multicolumn{5}{|l|}{ BMI } \\
\hline$<18$ & $12(22.2)$ & $6(11.1)$ & $36(66.7)$ & 0.032 \\
\hline $18-25$ & $41(31.3)$ & $34(26)$ & $56(42.7)$ & \\
\hline $25-30$ & $7(20.6)$ & $8(23.5)$ & $19(51.9)$ & \\
\hline$>\mathbf{3 0}$ & $7(46.7)$ & $1(6.7)$ & $7(46.7)$ & \\
\hline \multicolumn{5}{|l|}{ Smoking } \\
\hline Yes & $1(14.3)$ & $0(0)$ & $6(85.7)$ & 0.149 \\
\hline No & $66(29.1)$ & $49(21.6)$ & $112(49.3)$ & \\
\hline \multicolumn{5}{|l|}{ Co morbid Illness } \\
\hline Yes & $26(34.7)$ & $10(13.3)$ & $39(52.0)$ & 0.105 \\
\hline No & $41(25.8)$ & $39(24.5)$ & $79(49.7)$ & \\
\hline \multicolumn{5}{|l|}{ Hospital admission } \\
\hline Yes & $6(20.7)$ & $3(10.3)$ & $20(69.0)$ & 0.093 \\
\hline No & $61(29.8)$ & $46(22.4)$ & $98(47.8)$ & \\
\hline \multicolumn{5}{|l|}{ Unscheduled visit } \\
\hline Yes & $9(12.3)$ & $11(15.0)$ & $53(72.6)$ & 0.000 \\
\hline No & $58(36.0)$ & $38(23.6)$ & $65(40.4)$ & \\
\hline \multicolumn{5}{|l|}{ Type Treatment } \\
\hline SABA oral -Yes & $31(22.6)$ & $26(19.0)$ & $80(58.4)$ & 0.012 \\
\hline No & $36(37.1)$ & $23(23.7)$ & $38(39.2)$ & \\
\hline SABA inhaler-Yes & $20(15.4)$ & $23(17.7)$ & $87(66.9)$ & 0.000 \\
\hline No & $47(45.2)$ & $26(25.0)$ & $31(29.8)$ & \\
\hline OCS-Yes & $9(13.2)$ & 13(19.1) & $46(67.6)$ & 0.001 \\
\hline No & $58(34.9)$ & $36(21.7)$ & $72(43.4)$ & \\
\hline Antihistamine-Yes & $7(43.8)$ & $6(37.5)$ & $3(18.8)$ & 0.03 \\
\hline No & $60(27.5)$ & $43(19.7)$ & $115(52.8)$ & \\
\hline \multicolumn{5}{|l|}{ Personal rate } \\
\hline Uncontrolled & $18(12.0)$ & $34(22.7)$ & $98(65.3)$ & 0.000 \\
\hline controlled & $49(58.3)$ & $15(17.9)$ & $20(23.8)$ & \\
\hline
\end{tabular}


Table 3: Predictors of Asthma Control multinomial analysis, Chest Clinic, JUSH, August 2012 (Well controlled vs. poorly controlled)

\begin{tabular}{|c|c|c|c|c|c|}
\hline & & Control of $A$ & thma & OR & Sign. \\
\hline & & $\begin{array}{l}\text { Well controlled } \\
\text { No }(\%)\end{array}$ & $\begin{array}{l}\text { Very poorly } \\
\text { controlled } \\
\text { No }(\%)\end{array}$ & & \\
\hline Age & $14-34$ & 27 & 30 & $3.445(1.009-11.766)$ & .048 \\
\hline & $35-55$ & 25 & 57 & $1.700(0.546-5.295)$ & .365 \\
\hline & $>55$ & 15 & 31 & & \\
\hline Hospital admission & Yes & 6 & 20 & $0.509(0.120-2.166)$ & .361 \\
\hline & No & 61 & 98 & & \\
\hline Unscheduled visit & Yes & 9 & 53 & $0.197(0.070-0.555)$ & .002 \\
\hline & No & 58 & 65 & & \\
\hline Oral SABA use & Yes & 31 & 80 & $0.774(0.304-1.968)$ & .590 \\
\hline & No & 36 & 38 & & \\
\hline Inhaler SABA use & Yes & 20 & 87 & $0.190(0.074-0.488)$ & .001 \\
\hline & No & 47 & 31 & & \\
\hline OCS use & Yes & 9 & 46 & $0.247(0.084-0.728)$ & .011 \\
\hline & No & 58 & 72 & & \\
\hline Antihistamine use & Yes & 7 & 3 & $1.903(0.339-10.696)$ & .465 \\
\hline & No & 60 & 115 & & \\
\hline BMI & $<18$ & 12 & 36 & $0.719(0.092-5.594)$ & .752 \\
\hline & $18-25$ & 41 & 56 & $0.926(0.141-6.070)$ & .936 \\
\hline & $25-30$ & 7 & 19 & $0.395(0.050-3.137)$ & .379 \\
\hline & $>30$ & 7 & 7 & & \\
\hline Co morbid illness & Yes & 26 & 39 & $1.286(0.508-3.255)$ & .596 \\
\hline & No & 41 & 79 & & \\
\hline Personal rate of & Yes & 18 & 98 & $0.051(0.020-$ & .000 \\
\hline & No & 49 & 20 & & \\
\hline
\end{tabular}

\section{DISCUSSION}

The principal finding of this study is that asthma control in the chest clinic of JUSH is poor. Using the GINA based algorithm, $73.1 \%$ of the respondents were classified as having uncontrolled asthma and $42(26.2 \%)$ as having partly controlled asthma. Controlled asthma was documented in less than $1 \%$ of the subjects. But, when GINA based algorithm excluding PFT was used to assess asthma control, results were better. Only 79 (33.8\%) individuals had uncontrolled asthma and the proportion of subjects with controlled asthma raised to $3.8 \%$; it should be emphasized that assessing asthma control with only symptoms usually overestimates the result (7). For this reason, using the GINA based algorithm that includes PFT is more reliable.

The results observed were similar with the worldwide severity and control of asthma in the AIR trial in North America, Europe, Japan and the Asia-Pacific region with data from 10,939 patients in 29 countries (8). Another study in North Africa, the Maghreb Study, showed only $7.6 \%$ of the subjects were considered to have controlled and $50.9 \%$ to have uncontrolled asthma when the GINA based algorithm was used (7).

Using the ACT score also, a high number of individuals 167(71.4\%), scored $<19$ that corresponds to poor control of asthma in the 
current study. Sixty-six (28.6\%) individuals scored 20 and above which classified them as having well-controlled asthma, which is a better estimate of asthma control compared with results that used the GINA algorithm.

Another study done in Vietnam predicted GINA defined 'not controlled asthma' with a sensitivity of $70 \%$ and specificity of $93 \%$. The questionnaire score correlated well with treatment modifications and lung function parameters (FEV1 and PEF). The ACT is easily and quickly completed by patients and can serve as a useful tool in everyday practice to guide adjustments in asthma therapy (9). The GINA guideline on the other hand is based on expert consensus and has not yet been validated in real world practice (10, 11). Thus, the ACT is a more suitable instrument for assessing control when patients are directly asked about their symptoms (3).

This finding is comparable with a recent panEuropean cross-sectional survey done in 2008, with results of $57 \%$ of adult asthmatics had not well-controlled' asthma on a validated symptom instrument, with no improvement since 2006 (ACT score <19) (12).

The poor level of control likely resulted from the relatively very low proportion of respondents using the recommended prophylactic controller medication. Only 9 subjects $(3.8 \%)$ used inhaled corticosteroids alone or in association with longacting b-agonists. Most of the patients used only medications that quickly relieve asthma symptoms, but that has no role in controlling the underlying inflammation of the airways.

Although lower use of these controller medications is reported in different studies, a higher proportion of individuals do get the treatment in comparison with the asthmatic patients in the current study. For example, inhaled corticosteroids alone or in association with longacting b-agonists, which are the prophylactic treatments recommended by GINA, were used by 163 subjects (26.1\%) in North African AIRMAG study (3). Drug Utilization Assessment in Asthma Therapy in India done on 100 asthmatic patients in 2006 showed that $56 \%$ of the patients used inhaled corticosteroids during the study period (13).

The low use of inhaled corticosteroid, besides the readily unavailability of the drug, could be explained by the higher price of the medication than the other symptomatic treatments which can relieve but not control asthma. These drugs are often taken without prescriptions and may lead the patient to self-treatment.

Another factor associated with asthma control in the study was personal rate of asthma control in the past four weeks $\mathrm{p}<0.001$ (OR=0.051 95\% CI (0.020-0.128)). Eighty three individuals (71\%) reported their asthma to be rated as uncontrolled among the study group with really poorly controlled asthma $117(76.1 \%)$ when they were assessed by GINA that included spirometric assessment. From patients with severe persistent asthma, 37(86\%) rated their asthma as poorly controlled. This is in contrast to the Asthma Insights and Reality in Europe (AIRE) study where approximately 50\% of patients reporting severe persistent symptoms also considered their asthma to be completely or well-controlled (14). The high perceived rate of uncontrolled asthma in the current study can be explained by the poor underlying lung function result that showed $56.25 \%$ of the study subjects had FEV $1<80 \%$.

Finally, asthma control was also dependently associated with the individual patient's age group, $\mathrm{p}=0.048(\mathrm{OR}=3.445$ 95\% CI (1.009-11.766)). This finding was similar with the study done in the Netherlands, Disease control in the general practice patients with asthma, where patients inadequately controlled were usually older compared to those with a good disease control, $(\mathrm{OR}=2.395 \% \mathrm{CI}(1.38-3.85))(15)$.

One of the potential limitations of this study was difficulty in obtaining the maximum respiratory effort to generate the FEV1. Only 160 people $(68 \%)$ were able to produce acceptable FEV1 measurements; the rest $74(32 \%)$ could neither reproduce acceptable results nor excluded using the exclusion criteria. Therefore, they were assessed for control of asthma using GINA guidelines excluding LFT and by the standardized ACT questionnaire. The problems identified in the patients to reproduce acceptable results were lack of proper understanding on how to perform spirometry and fear of precipitating asthma symptoms by taking a deep and maximum breath.

A second drawback is that the sample size of 234 for whom asthma control was measured by the validated ACT measurement and 160 individuals on whom appropriate spirometry was done, while being considerably enough, gives a reduced statistical power among subgroup 
multinomial analyses in patients taking different treatment and other subgroups (Table 3). Therefore, studies on larger samples are needed to monitor trends of asthma control and identify further independent factors for control.

\section{ACKNOWLEDGMENTS}

We would like to acknowledge Jimma University for giving us this chance to conduct this study and for the financial support that was provided. We would also like to thank the Department of Internal Medicine for the supports it rendered us in accomplishing this research, and the Department of Pediatrics and child health for their cooperation in providing us a spirometer to conduct our study. We are grateful to Zewdie Birhanu, Department of Health Education and Behavioral Sciences, for his assistance in the data processing and analysis. Our final acknowledgement also goes to Binyam Kebede, a pharmacist, who provided us with mouth pieces for the spirometry machine.

\section{REFERENCES}

1. Global strategy for asthma management and prevention, global initiative for asthma (GINA) 2010 www.ginasthma.org.

2. National Asthma Education and Prevention Program: Expert panel report III: Guidelines for the diagnosis and management of asthma. Bethesda, MD: National Heart, Lung, and Blood Institute, 2007.

3. Ali B, Hend B, Salim N, et al. Control of Asthma Maghreb, results of the AIRMAG study. Respiratory Medicine 2009;103:12-20.

4. Michael S, Christine A. S, James T. Li, et al. Asthma Control Test Reliability, validity, and responsiveness in patients not previously followed by asthma specialists. J Allergy Clin Immunol 2006; 117:549-56.

5. Osborne ML, Pedula KL, O'Hollaren M, et al. Assessing future need for acute care in adult asthmatics: the Profile of Asthma Risk Study. Chest 2007;132:1151.

6. Sukhpal K, Behera D, Gupta D et al. Demographic and Environmental factors in patients of bronchial asthma. Indian J Allergy Asthma Immunol 2008;22(2):85-89.

7. Ali B, Hend B, Salim N, et al. Control of Asthma Maghreb: results of the AIRMAG study. Respiratory Medicine 2009;103:12-20.

8. Klaus F, Mitsuru A, Christopher K, et al. Worldwide severity and control of asthma in children and adults: The Global Asthma Insights and Reality surveys. J Allergy Clin Immunol 2004;114:40-7.

9. Vinh Nhu Nguyena, Niels Chavannesb, Lan Thi Tuyet Lec, et al. The Asthma Control Test (ACT) as an alternative tool to Global Initiative for Asthma (GINA) guideline criteria for assessing asthma control in Vietnamese outpatients. Prim Care Respir J 2012; 21(1): 85-89.

10. Jose MO, Santiago Q, Berta J, et al. Measurement of asthma control according to 2006 Global Initiative on Asthma Guidelines: MAGIC Study. Respiratory Research 2012;13:50.

11. Francisco Javier Álvarez-Gutiérrez, Juan Francisco Medina-Gallardo, Pablo PérezNavarro, et al. Relationship of the Asthma Control Test (ACT) with Lung Function, Levels of Exhaled NitricOxide and Control According to the Global Initiative for Asthma (GINA). Arch Bronconeumol. 2010; 46(7):370-377.

12. Nasser Al-B and Joan B. Asthma Control in Oman National Results within the Asthma Insights and Reality in the Gulf and the Near East (AIRGNE) Study. Sultan Qaboos Univ Med J 2011;1:45-51.

13. Arumugam V, Preeti K, Vijay J, et al. Drug Utilization Assessment in Asthma Therapy through Prescription Monitoring at Dehradun Hospitals. Indian J Allergy Asthma Immunol 2008;22(1):15-18.

14. K.F. Rabe, P.A. Vermeire, J.B. Soriano, et al. Clinic management of asthma in 1999: the Asthma Insights and Reality in Europe (AIRE) study. Eur Respir J 2000;16:802-807.

15. Hanneke W, Didi M.W. K, Arlette E. H, et al. Disease control in general practice patients with asthma. Primary Care Respiratory Journal 2004;13: 89-98. 